\title{
Alternativas para o gerenciamento de lodo de sistemas descentralizados de tratamento de esgotos de áreas rurais
}

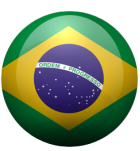 \\ Adriano Luiz Tonetti \\ Engenheiro Químico, Doutor em Engenharia Civil. Professor da Faculdade de Engenharia Civil, Arquitetura \\ e Urbanismo, da Universidade Estadual de Campinas (Unicamp). Campinas [SP] Brasil. \\ <adriano@fec.unicamp.br>. \\ Natália Cangussu Duarte \\ Engenheira Civil. Mestranda da Faculdade de Engenharia Civil, Arquitetura e Urbanismo. Universidade \\ Estadual de Campinas (Unicamp). Campinas [SP] Brasil.

\section{Isabel Campos Salles Figueiredo} \\ Bióloga. Doutoranda da Faculdade de Engenharia Civil, Arquitetura e Urbanismo. Universidade Estadual de \\ Campinas (Unicamp). Campinas [SP] Brasil.

\section{Ana Lúcia Brasil} \\ Engenheira Sanitarista. Coordenadora da Câmara Técnica de Saneamento e Saúde em Comunidades \\ Isoladas da Associação Brasileira de Engenharia Sanitária e Ambiental (ABES, Seção São Paulo). São Paulo \\ [SP] Brasil.
}

\section{Resumo}

A inexistência de coleta e tratamento de águas residuais ainda é um problema comum no Brasil. Normalmente a solução adotada nas áreas rurais envolve o lançamento do esgoto em buracos escavados no solo, denominados de fossas negras ou rudimentares. As normas brasileiras (NBR 7229, 1993 e NBR 13969, 1997) apontam que o sistema mais apropriado a ser implantado nestes casos seria o tanque séptico associado a um sistema de pós-tratamento. No entanto, esse sistema produz um lodo que deve ser adequadamente gerenciado. Desse modo, este trabalho discute três opções de gerenciamento do lodo gerado nos tanques sépticos instalados em uma área rural do município de Campinas (São Paulo, Brasil): 1) Remoção do lodo por empresa terceirizada; 2) Gerenciamento do lodo pela empresa de saneamento do município; 3) Gerenciamento de lodo pela comunidade. Levando em conta somente fatores econômicos foi encontrado que a forma mais vantajosa seria o gerenciamento do lodo pela empresa de saneamento do município.

\section{Palavras-chave}

Tratamento de esgoto. Tratamento de esgoto descentralizado. Lodo. Lodo. Gerenciamento. Tanque séptico.

\section{Alternatives for the management of sludge from decentralized sewage treatment systems in rural areas}

\begin{abstract}
The lack of wastewater collection and treatment is a common issue in Brazil. The usual solution adopted in rural areas is throwing the wastewater directly in dug-out holes, which are known as pit latrines. Brazilian regulations (NBR 7229, 1993 and NBR 13969, 1997) state that the most appropriate treatment system in these cases would be a septic tank followed by a post treatment system. However, this alternative produces sludge that needs to be properly managed. Thus, three options for management of sludge from a rural area from the city of Campinas (São Paulo) are discussed in this work. 1) Sludge removal by outsourced company; 2) Sludge management by city's sanitation company; 3) Sludge management by local community. Considering only economic factors, it was concluded that the sludge management by city's sanitation company would be the most beneficial alternative for the community.
\end{abstract}

\section{Keywords}

Wastewater treatment. Wastewater treatment decentralized. Sludge. Sludge management. Septic tank. 


\section{Introdução}

$\mathrm{Na}$ área rural brasileira há a disseminação de sistemas descentralizados unifamiliares. Nestes sistemas ocorre a associação do tanque séptico com a aplicação no solo por meio de sumidouros rudimentares. Também existe a prática da retirada do tanque séptico desta associação de reatores. Neste caso, o esgoto é lançado diretamente em buracos profundos escavados no solo, tipicamente chamados de fossa negra.

Por sua vez, as normas brasileiras que orientam a elaboração de projetos para o tratamento de esgotos em áreas rurais ou isoladas (NBR 7229, 1993 e NBR 13969, 1997) recomendam que em todos os casos seja adotado um tanque séptico seguido de algum pós-tratamento (Tonen et al., 2015; Tonetti et al., 2012).

Dentro deste contexto, em diversos estados que compõem o território brasileiro há a discussão sobre como adequar a disposição dos esgotos na área rural, tendo-se em vista a universalização do saneamento. No entanto, na imensa maioria dos casos, as instituições envolvidas com o saneamento rural somente estão preocupadas com a instalação dos sistemas de tratamento de esgotos. Não há praticamente nenhuma atenção ao gerenciamento destes sistemas.

É sabido que os tanques sépticos são sistemas robustos, fáceis de serem construídos e apresentam uma eficiência de remoção dos sólidos suspensos que pode variar de 60 a $80 \%$ (USEPA, 2002). 0 tempo de detenção hidráulica varia de 12 a 24 horas, dependendo da população contribuinte (NBR 7229, 1993). De modo simplista, opera como um tanque de sedimentação e de digestão do lodo formado, o qual apresenta grandes variações no teor de umidade, quantidade de sólidos, DQO e DBO (USEPA, 2002; Carvalho \& Andreoli, 2015), dificultando seu condicionamento e posterior aproveitamento.

No Brasil, estima-se que $22 \%$ dos domicílios possuem tanque séptico (IBGE, 2011), o que equivale a aproximadamente 23 milhões de unidades. Porém não há qualquer levantamento quanto ao destino do lodo produzido nestes reatores. Possivelmente, na imensa maioria dos casos esse material não é retirado do tanque séptico, fazendo com que o reator funcione somente como uma caixa de passagem para o esgoto. Outro destino comum seria seu lançamento em corpos hídricos ou diretamente no solo, podendo causar danos ambientais e à saúde humana.

Uma alternativa de gerenciamento seria o uso de leitos de secagem para seu desaguamento (Van Haandel \& Lettinga, 1994). Isso reduziria sua umidade e volume e também possibilitaria o aproveitamento deste material em culturas agrícolas. Esta alternativa apresenta facilidade operacional e pequeno consumo energético (Van Haandel \& Lettinga, 1994). 0 tempo de secagem do lodo deve ser de três meses para que ocorra a sua desinfecção (CONAMA 375, 2006).

As principais desvantagens desse sistema são: o risco de contaminação do lençol freático em caso de impermeabilização mal feita; a ocorrência de maus odores e a atração de insetos e animais nocivos à saúde humana (WEF, 1996). Porém, deve-se ter em mente que o lodo possui em sua composição grande quantidade de nutrientes essenciais ao desenvolvimento das plantas, o que lhe confere um grande potencial para uso como fertilizante (Paixão Filho et al., 2014; Gabrielli et al., 2015; Marinho et al., 2013).

O uso de lodo na agricultura pode trazer muitos benefícios, porém a qualidade do lodo para esta finalidade deve ser bem controlada, para que não ofereça risco à população ou ao meio ambiente (Paixão Filho et al., 2014). A presença de patógenos, metais pesados e/ou outros poluentes pode provocar impactos ambientais muito negativos e muitas vezes irreversíveis, abalando também a confiança popular no sistema de tratamento.

O lançamento do lodo nas estações de tratamento de esgoto (ETE) também pode ser uma alternativa adequada, desde que seu projeto contemple a possibilidade de tratamento da carga orgânica adicional e que seja prevista uma estrutura específica para o recebimento do lodo (Carvalho \& Andreoli, 2015). Essa estrutura deve considerar as manobras dos caminhões, a descarga do lodo de forma controlada e sistemas de pré-tratamento específicos para o lodo 
(Carvalho \& Andreoli, 2015). Na entrada da ETE que receberá a contribuição de lodo das fossas, pode ser instalado um tanque de recepção, adequadamente dimensionado, para distribuir esta contribuição de maneira uniforme ao longo do tempo (Carvalho \& Andreoli, 2015).

Deste modo, este trabalho tem como objetivo avaliar economicamente diferentes formas de gerenciamento do lodo produzido em tanques sépticos. Para isso foi feito um estudo de caso envolvendo uma hipotética comunidade rural localizada no município de Campinas (Brasil). No estudo foram avaliadas três alternativas de gerenciamento: 1) Remoção do lodo por empresa terceirizada; 2) Gerenciamento do lodo pela empresa de saneamento municipal; 3) Gerenciamento de lodo pela própria comunidade geradora.

\section{Metodologia}

Neste projeto foram avaliadas diferentes formas de gerenciar o lodo gerado em uma área rural hipotética localizada no município de Campinas (São Paulo, Brasil). Cabe destacar que o município de Campinas possui uma população total de um milhão de habitantes e está no centro de uma das regiões metropolitana mais ricas do Brasil.

No estudo foram consideradas 50 propriedades (cerca de duzentos e cinquenta moradores) e foi considerado que cada propriedade teria um tanque séptico. Para o gerenciamento do lodo produzido neste reator foram consideradas as seguintes alternativas: 1) Remoção por empresa terceirizada; 2) Gerenciamento pela empresa de saneamento do município; 3) Gerenciamento de lodo pela própria comunidade geradora.

No caso da remoção do lodo por empresa terceirizada foi feito um levantamento junto a diferentes empresas capacitadas a retirá-lo dos tanques sépticos por meio de caminhões limpa fossa.

No segundo caso foi considerado o gerenciamento do lodo pela empresa de saneamento do município de Campinas. Para isso foi feita uma estimativa de gastos por parte da empresa municipal de saneamento caso ela executasse este serviço. Foi considerado que a empresa necessitaria de um caminhão limpa-fossa e dois funcionários para a realização do serviço.

No terceiro caso, onde o gerenciamento de lodo seria feito pela própria comunidade, foi considerado que seria necessária a aquisição de uma bomba de recalque de lodo para sua remoção do interior dos tanques sépticos. Além disso, seria necessária a construção de um leito de secagem para desaguamento do lodo. Também foi considerada a mão de obra necessária para a manutenção do leito e controle da secagem.

Todos os valores em Reais (R\$) apresentados foram obtidos em um levantamento realizado no mês de outubro de 2016.

\section{Resultados e discussão}

Em cada uma das três alternativas foi considerado que cada uma das 50 famílias era composta por cinco pessoas $(\mathrm{N})$ e possuiria um tanque séptico. Desse modo, foi feito um dimensionamento preliminar de acordo com a Equação 1 proposta pela norma brasileira (NBR 7229, 1993).

$$
\mathrm{V}=1000+\mathrm{N} \cdot\left(\mathrm{C} \cdot \mathrm{T}+\mathrm{K} \cdot \mathrm{L}_{\mathrm{f}}\right)
$$

Onde: $\mathrm{V}$ é o volume útil; $\mathrm{N}$ é o número de pessoas contribuintes; $\mathrm{C}$ é a contribuição de despejos; T é o período de detenção; K é a taxa de acumulação de lodo digerido e Lf é a contribuição de lodo fresco.

Desse modo, considerando-se uma residência de padrão médio, com contribuição de esgotos (C) de 130 litros por pessoa por dia, uma contribuição de lodo fresco $\left(\mathrm{L}_{\mathrm{f}}\right)$ de 1 litro por pessoa por dia, um período de detenção (T) de 1 dia, um intervalo de limpeza de 1 ano e uma taxa de 
acumulação de lodo digerido (K) de 57 dias, o volume obtido para este tanque séptico foi de 1935 litros. Por facilidade construtiva optou-se por adotar um tanque séptico de 2.000 litros.

Em todas as situações avaliadas foi considerado que no momento de retirada do lodo, todo o resíduo presente no interior do tanque séptico seria removido. Ou seja, seriam esgotados o lodo e o esgoto presentes no reator.

\subsection{Alternativa 1: Contratação de empresa terceirizada para remoção do lodo}

Neste caso foi solicitado a três empresas do município de Campinas (São Paulo, Brasil) especializadas na remoção de lodo de tanques sépticos um orçamento para a prestação desse serviço de limpeza. 0 valor mínimo cobrado para a retirada e destinação do lodo produzido foi de $\mathrm{R} \$$ 240,00 por tanque séptico. Logo o gasto mensal de cada família para que tivesse seu tanque séptico limpo uma vez ao ano seria de $\mathrm{R} \$ 20,00$.

\subsection{Alternativa 2: A empresa de saneamento do município assumiria o gerenciamento do lodo}

Nesta avaliação foi feita uma estimativa de custos considerando-se que a empresa de saneamento do município de Campinas fizesse este gerenciamento e repassasse os gastos de operação para a população. Para isso foi considerado que a empresa de saneamento compraria um caminhão limpa fossa e empregaria dois funcionários nas atividades envolvidas.

O custo com a mão de obra foi estimado a partir do salário que a empresa paga a um funcionário no transporte de resíduos. Assim, foi considerado um custo total para os dois funcionários igual a $\mathrm{R} \$ 6.268,74$, incluindo todos os encargos trabalhistas existentes no Brasil.

Quanto ao caminhão limpa fossa foi considerado a compra de um veículo com capacidade para armazenar $8 \mathrm{~m}^{3}$ de resíduos. Após pesquisa de preço pela Tabela Fipe (FIPE, 2016) foi encontrado que o valor deste veículo seria $\mathrm{R} \$ 207.800,00$ (apenas o veículo). Seria necessária também a compra de um tanque de armazenamento. Após pesquisa com três fabricantes, foi encontrado que este teria um valor aproximado de $\mathrm{R} \$ 40.000,00$, totalizando um gasto de $\mathrm{R} \$ 247.800,00$ com o veículo.

Também foi considerado que o caminhão sairia da empresa de saneamento vazio e iria até a comunidade em estudo. Ao longo do dia coletaria o lodo de quatro tanques sépticos, ou o equivalente a $8 \mathrm{~m}^{3}$. Ao final do dia levaria o resíduo coletado até a disposição final. Na cidade de Campinas esta disposição seria em uma estação de tratamento de esgotos preparada para tal recebimento.

Foi considerado que este caminhão atenderia não somente a localidade em estudo, mas toda a área rural do município. Foi adotado que em média este caminhão percorreria uma distância de $60 \mathrm{~km}$ por dia e atuaria 20 dias por mês. Como a estação de tratamento de esgotos que receberia este lodo atende uma população de 250.000 pessoas, foi considerado que a disposição do lodo em conjunto com o esgoto bruto afluente não acarretaria em aumento de custo para a operação da estação de tratamento.

Os custos mensais com o caminhão podem ser divididos em custos fixos (depreciação, remuneração de capital, impostos e seguros) e custos variáveis (manutenção, pneus, combustível, óleo, lavagens e graxas). Estes custos foram estimados com base em levantamento realizado pela empresa RLV Soluções Empresariais (RLV Soluções Empresariais, 2014). Esta empresa brasileira presta consultoria na área de custos com logística e transporte.

Os custos fixos mensais estimados seriam então de $R \$ 2.777,35$ e os custos variáveis mensais seriam de $\mathrm{R} \$ 1,35$ por quilometro percorrido. 0 percurso máximo que o veículo percorreria diariamente entre o local em que permaneceria no período noturno e o extremo da cidade seria de $60 \mathrm{Km}$ (ida e volta). Deste modo, foi considerado que este caminhão percorreria $60 \mathrm{~km}$ por dia em 20 dias por mês. Logo, seu custo variável mensal seria $\mathrm{R} \$ 1.620,00$. 0 gasto mensal total com o caminhão (custo fixo e variável) seria igual a $\mathrm{R} \$ 4.397,35$. 
Ao incluir os dois funcionários que seriam responsáveis pelo caminhão, o custo mensal para a empresa de saneamento seria igual a $R \$ 10.666,09$. Neste caso, ao longo de toda a jornada diária de trabalho estes funcionários poderiam realizar a remoção de $8 \mathrm{~m}^{3}$ de lodo por dia. Isso totalizaria $160 \mathrm{~m}^{3}$ de lodo por mês. Ou seja, o custo por litro de lodo retirado e adequadamente destinado seria de $\mathrm{R} \$ 0,07$.

Considerando-se o conjunto de 50 famílias da área de estudo, o custo para a remoção anual do lodo seria igual a: $\mathrm{R} \$ 0,07 \times 2.000 \times 50=\mathrm{R} \$ 7.000,00$. Logo, a conta mensal a ser paga por cada família pelo gerenciamento do lodo seria de $\mathrm{R} \$ 11,67$.

É importante destacar que os funcionários responsáveis pelo caminhão poderiam ser preparados para atuarem como agentes do saneamento rural. Ou seja, eles poderiam monitorar o funcionamento do tanque séptico e o pós-tratamento do efluente gerado. Desse modo, poderiam orientar as famílias quanto aos procedimentos mais adequados de manutenção e operação do sistema de tratamento.

\subsection{Alternativa 3: A própria comunidade assumiria a responsabilidade pelo gerenciamento do lodo}

Nesta forma de gerenciamento foi considerado que a comunidade adquiriria uma bomba para remover o lodo do interior dos tanques sépticos. Para a execução desta atividade foi encontrado que a bomba mais adequada possuía um custo de $\mathrm{R} \$ 1.385,00$. Considerando-se uma vida útil de 10 anos e um valor residual de $10 \%$, o custo anual da bomba seria de $\mathrm{R} \$ 177,71$. Tal cálculo foi realizado baseado em Newnan et al. (2009) e em uma taxa mínima de atratividade de $6 \%$ ao ano.

A comunidade também necessitaria construir um leito de secagem para dispor o lodo removido. Optou-se por um único leito de secagem para todas as 50 residências, assim, seguindo-se as orientações da norma brasileira (NBR 12209, 2011) para o dimensionamento do leito de secagem e considerando-se que o lodo do tanque séptico tem um teor de sólidos de $40 \mathrm{gL}^{-1}$ (Metcalf \& Eddy, 1995) foi encontrado que o leito de secagem teria altura de 0,50 m e área de $290 \mathrm{~m}^{2}$. Para sua construção foi considerada uma obra que duraria dois meses e haveria a necessidade de mão de obra, areia, cimento, cal, brita, blocos, telhas transparentes, impermeabilizante e manta filtrante. Assim, seu custo total seria de R $64.082,59$ (Tabela 1). No caso não foi levada em conta a terraplanagem do terreno e construção e aterramento das valas.

Tabela 1. Custo com materiais e mão de obra para a construção do leito de secagem.

\begin{tabular}{|l|c|c|c|c|}
\hline \multicolumn{1}{|c|}{ Material } & Unidade & Preço (R\$) & Quantidade & Custo Total (R\$) \\
\hline Mão de obra & $\mathrm{h}$ & 17,96 & 1280 & 22988,01 \\
\hline Areia & $\mathrm{m}^{3}$ & 67,37 & 75 & 5052,75 \\
\hline Cimento & $\mathrm{Kg}$ & 0,42 & 810 & 338,74 \\
\hline Cal & Saco de $20 \mathrm{~kg}$ & 9,39 & 115 & 1079,85 \\
\hline Blocos & Unidade & 0,47 & 4298 & 2012,97 \\
Impermeabilizante & Kg & 7,18 & 339 & 2434,02 \\
\hline Telha transparente & Unidade & 16,79 & 497 & 8344,63 \\
\hline Brita & m ${ }^{3}$ & 73,51 & 73 & 5366,23 \\
\hline Elemento filtrante & Unidade & 418,10 & 23 & 9616,30 \\
\hline \multicolumn{5}{|c|}{ Custo total } \\
\hline
\end{tabular}


Ao considerar uma vida útil de 20 anos e valor residual nulo para este leito de secagem, seu custo anual para uma taxa mínima de atratividade de $6 \%$ ao ano seria de $\mathrm{R} \$ 5.588,00$ (Newnan et al., 2009).

Para o transporte do lodo dos tanques sépticos até o leito de secagem foi considerada a aquisição de um reservatório de $2,0 \mathrm{~m}^{3}$. 0 valor desse reservatório é de $\mathrm{R} \$ 1.590,00$. Seu custo anual, calculado conforme Newnan et al. (2009), para uma vida útil de 10 anos, valor residual de $10 \%$ e taxa mínima de atratividade de $6 \%$ seria de R $\$ 204,01$. Foi considerado que o transporte do lodo neste reservatório seria feito em tratores existentes nas próprias propriedades. Não foi contabilizado o gasto com combustível.

A comunidade também necessitaria de mão de obra para remoção do lodo dos tanques sépticos, bem como para revolvê-lo e retirá-lo do leito de secagem. 0 valor médio para este profissional no município de Campinas era de aproximadamente $\mathrm{R} \$ 200,00$ por dia. No cálculo foi considerado que para a retirada do lodo de cada tanque séptico haveria um dispêndio de 2 horas, totalizando 4 reatores limpos por dia de trabalho, o que equivale a 12,5 dias para a limpeza de todos os reatores. Também foi considerado que este profissional precisaria atuar no leito de secagem ao menos uma vez por semana para monitorar a secagem do lodo por um período de 3 meses. Isso totalizaria 12 dias de trabalho. Logo, haveria a necessidade de 24,5 dias (12,5 dias + 12 dias) de atuação para o gerenciamento do lodo. Considerando-se para 25 dias, o custo total do serviço seria de $\mathrm{R} \$ 5.000,00$ por ano.

É importante destacar que neste estudo não foi considerado que algum morador da própria localidade fizesse o gerenciamento destas atividades de retirada do lodo do tanque séptico e do leito de secagem. Foi feita tal consideração em função do período total de tempo que estas atividades demandariam (24,5 dias ou quase 1 mês).

Realizando a totalização dos custos (aquisição de bomba e reservatório, construção do leito e manutenção e operação) haveria a necessidade de despender $\mathrm{R} \$ 10.969,72$ por ano. Isso equivale a $\mathrm{R} \$ 18,28$ por família por mês.

Deve-se destacar que nesta avaliação não foram considerados os custos e benefícios ocasionados pelo emprego do lodo no solo.

\subsection{Comparação das alternativas}

Na Tabela 2 estão apresentados os resultados obtidos para as três alternativas estudadas. Foi considerado que todas elas são tecnicamente viáveis e bem aceitas pela população rural. Além disso, na escolha da melhor alternativa foi levado em conta somente o fator econômico do empreendimento.

Tabela 2. Comparação de custos de cada alternativa.

\begin{tabular}{|l|c|c|c|}
\hline \multicolumn{1}{|c|}{ Alternativa } & $\begin{array}{c}\text { Custo anual } \\
\text { para a } \\
\text { comunidade }\end{array}$ & $\begin{array}{c}\text { Custo anual } \\
\text { para cada } \\
\text { família }\end{array}$ & $\begin{array}{c}\text { Custo mensal } \\
\text { para cada } \\
\text { família }\end{array}$ \\
\hline $\begin{array}{l}1 \text { - Contratação de empresa terceirizada para } \\
\text { remoção do lodo }\end{array}$ & $\mathrm{R} \$ 12.000,00$ & $\mathrm{R} \$ 240,00$ & $\mathrm{R} \$ 20,00$ \\
\hline $\begin{array}{l}2 \text { - A empresa de saneamento do município } \\
\text { assumiria o gerenciamento do lodo }\end{array}$ & $\mathrm{R} \$ 7.000,00$ & $\mathrm{R} \$ 140,00$ & $\mathrm{R} \$ 11,67$ \\
\hline $\begin{array}{l}3 \text { - A própria comunidade assumiria a } \\
\text { responsabilidade pelo gerenciamento do lodo }\end{array}$ & $\mathrm{R} \$ 10.969,72$ & $\mathrm{R} \$ 219,39$ & $\mathrm{R} \$ 18,28$ \\
\hline
\end{tabular}

Pode ser notado que a opção mais vantajosa para a comunidade rural do município de Campinas (São Paulo, Brasil) seria a alternativa 2. No caso, seria mais vantajoso que a própria empresa de saneamento do município assumisse o gerenciamento do lodo. 
Cabe ressaltar que esta escolha está fincada em uma avaliação puramente econômica. Não foram levados em consideração aspectos ambientais ou de sustentabilidade. Por exemplo, não foram consideradas as emissões de gases de efeito estufa emitidos pelo veículo. Também não foi estimado o benefício do gerenciamento do lodo na própria comunidade, procurando manter o uso dos nutrientes no próprio local de geração.

Outro ponto não considerado foi o acréscimo do lucro na alternativa 2. Ou seja, a empresa de saneamento obteria lucro na retirada de lodo das comunidades rurais do município em estudo.

Cabe destacar que a alternativa 2 foi mais barata que a 3, na qual a comunidade gerenciaria o lodo produzido. Uma possível explicação para essa constatação seria a economia de escala. No caso, a comunidade estaria arcando com custos que não seriam distribuídos por uma grande população atendida. No entanto, cabem estudos que façam uma avaliação mais ampla destas alternativas, levando em conta a sustentabilidade ambiental do empreendimento e o reuso dos nutrientes presentes no lodo.

Outra limitação do estudo diz respeito ao próprio porte do município de Campinas. Ele está no centro de uma das regiões mais ricas do Brasil. Logo, há a possibilidade de aplicação de qualquer uma das alternativas propostas. Não há limitações quanto a disponibilidade de empresas terceirizadas, estações de tratamento de esgotos ou pessoal capacitado a realizar as funções exigidas nas alternativas avaliadas. Tal característica é bastante incomum no restante dos municípios brasileiros.

\section{Conclusões}

Considerando o município de Campinas (São Paulo, Brasil), que é o centro de uma das regiões mais ricas do país, e as três alternativas discutidas neste trabalho para o gerenciamento do lodo produzido em sua comunidade rural: 1 - Contratação de empresa terceirizada para remoção do lodo; 2 - A empresa de saneamento do município assumiria o gerenciamento do lodo; $3-\mathrm{A}$ própria comunidade assumiria a responsabilidade pelo gerenciamento do lodo, e levando em conta somente aspectos econômicos, foi constatado que a alternativa mais vantajosa para a comunidade seria que a empresa de saneamento do município assumisse o gerenciamento do lodo.

\subsection{Agradecimentos}

Os autores gostariam de agradecer ao CNPq (Processo 471833/2011-8) e a FAPESP (Processo 2017/07490-4) pelo financiamento do estudo.

\section{Referências}

ABNT NBR 7229 (1993). Projeto, construção e operação de sistemas de tanques sépticos. Rio de Janeiro: ABNT, 15 p.

ABNT NBR 12209 (2011). Elaboração de projetos hidráulico-sanitários de estações de tratamento de esgotos sanitários. Rio de Janeiro: ABNT, 53 p.

ABNT NBR 13969 (1997). Tanques sépticos - Unidades de tratamento complementar e disposição final dos efluentes líquidos - Projeto, construção e operação. Rio de Janeiro: ABNT, 60 p.

Carvalho, E. H., \& Andreoli, C. V. (2015). Lodos de fossa e tanque séptico: orientações para Definição de Alternativas de Gestão e Destinação. 1. ed. 450p.

CONAMA (2006). Resolução número 375, de 29 de agosto de 2006. Define critérios e procedimen-tos, para o uso agrícola de lodos de esgoto gerados em estações de tratamento de esgoto sanitário e seus produtos derivados, e dá outras providências. Ministério do Desenvolvimento Urbano e Meio Ambiente.

FIPE. Tabela FIPE. Recuperado de: <http://veiculos.fipe.org.br/\#caminhao>.

(C) Labor \& Engenho, Campinas [SP] Brasil, v.12, n.1, p.145-152, jan./mar. 2018. 
Gabrielli, G. et al. (2015). Ambiance rose production and nutrient supply in soil irrigated with treated sewage. Revista Brasileira de Engenharia Agrícola e Ambiental, 19 (8) 755-759.

IBGE. Recuperado de: < http://www.ibge.gov.br >.

Marinho, L. E. O., Tonetti, A. L., Stefanutti, R., \& Coraucci Filho, B. (2013). Application of reclaimed wastewater in the irrigation of rosebushes. Water, Air and Soil Pollution, 224, 1669-1676.

Metcalf \& Eddy (1995). Wastewater engineering treatment disposal reuse. 3. ed. New York: McGraw-Hill.

Newnan, D. G., Eschenbach, T. G., \& Lavelle, J. P. (2009). Engineering Economic Analysis (10th ed., 567 p.). Oxford: Oxford University Press.

Paixão Filho, J. L., Gabrielli, G., Coraucci Filho, B., \& Tonetti, A. L. (2014) Use of stabilization pond sludge in cultivation of roses. Revista Brasileira de Engenharia Agrícola e Ambiental, 18(1), 85-89.

RLV Soluções Empresariais (2014). Planilhas de Custos Operacionais 2014. Recuperado de: $<w w w . g u i a d o t r c . c o m . b r / t r u c k i n f o / c a m i n h o e s \_p e s a d o s . x l s>$.

Tonetti, A. L., Coraucci Filho, B., Nicolau, C. E., Barbosa, M., \& Tonon, D. (2012). Tratamento de esgoto e produção de água de reúso com o emprego de filtros de areia. Revista Engenharia Sanitária e Ambiental, 17(1), 287-294. Recuperado de: http://dx.doi.org/10.1590/S1413-41522012000300005.

Tonon, D., Tonetti, A. L., Coraucci Filho, B., \& Bueno, D. A. C. (2015). Wastewater treatment by anaerobic filter and sand filter: Hydraulic loading rates for removing organic matter, phosphorus, pathogens and nitrogen in tropical countries. Ecological Engineering, 82, 583-589. Recuperado de: http://dx.doi.org/ 10.1016/j.ecoleng.2015.05.018.

U.S. EPA (2002). Onsite Wastewater Treatment Systems Manual, EPA-625/R-00/008, February.

Van Haandel, A. C., \& Lettinga, G. (1994). Anaerobic sewage treatment: a practical guide for regions with a hot climate. John Wiley and Sons, 1994. 222 p.

WEF (1996). Operation of municipal wastewater treatment plants. Manual of Practice. $5^{\text {th }}$ ed. 